\title{
Inquiry Base Experiment: The Effect of Plasma on Glass Surface Properties
}

\author{
http://dx.doi.org/10.3991/ijep.v6i2.5317 \\ L. R. Kabot, T.M. Worden, A.K. Matsushita, R.X. Hernandez, N. Abramzon \\ Cal Poly Pomona, Pomona, CA, USA
}

\begin{abstract}
In this paper we present an inquiry-based experiment for an undergraduate plasma course. Students were exposed to a laboratory experience that very closely resembles real-life research by performing surface modification experiments using gas discharge plasma. This experiment demonstrates to students the effect of plasma on surface properties.
\end{abstract}

Index Terms-undergraduate education, plasma, glass, surface properties, inquiry-based lab

\section{INTRODUCTION}

Over the past two decades, scientific research on how students learn in the STEM fields has made tremendous progress [1-2]. It is now generally acknowledged among science and engineering education researchers that the traditional lecture format where students passively absorb knowledge is not a particularly effective learning environment [3-6]. As a consequence, interactive and engaging practices, such as inquiry-based techniques and undergraduate research experiences are being used more and more in physics, science, and engineering curricula [7-10].

Because of the expense and amount of faculty time required to support student research, many students will not have the opportunity to work under a mentor on original research as undergraduates. However, many of the key elements that make undergraduate research a valuable learning experience can be incorporated into courses and programs that are part of the standard undergraduate curriculum, making the benefits of research experience available to a broader base of students [11,12]. We present elements of research experience that were introduced in an undergraduate plasma course.

Plasma surface modification is an effective way to control the surface energy and chemical properties of substrates without affecting the bulk material [13-15].

Surface preparation through surface activation and contamination removal, by plasma processing is widely used in industries such as the microelectronic and optoelectronic device assembly, printed circuit board (PCB) manufacturing and medical device manufacturing industries. Surface preparation by plasma removes contaminants from the surface and activates the surface for various applications including improving adhesion and promoting fluid flow. Surface activation is a process where surface functional groups are replaced with different atoms or chemical groups from the plasma.

Contact angle measurements have been used for many years to assess surface wettability and roughness. The contact angle is defined as the angle between the tangent to the liquid-air interface and the tangent to the solid-air interface, as shown in the figure. Contact angles less than $90^{\circ}$ correspond to hydrophilic surfaces, while hydrophobic surfaces are defined by larger contact angles.

We investigate the effect of plasma treatment of a glass slide on the contact angle. Water contact angle versus different plasma parameters was measured. This investigation is suitable as a class project assigned to undergraduates in an upper-division plasma course.

\section{EXPERIMENTAL METHODS}

The experiment was preformed following the inquirybased approach; students were given minimal instruction and were asked to design an experiment to study the effect of plasma on glass surfaces.

We implemented the research experience in the PHY 422 Plasma course at Cal Poly Pomona. PHY422 is an upper division lecture course design for physics and engineering majors. The lectures are scheduled in two-hour per week sessions. All class activities take place in a dedicated lab classroom. There are six fixed tables in the room; each seats four or five students. While PHY 422 is not a lab course, the course does seek to model hands-on research and industry practices. Activities include experimental measurements and active participation, as well as small-group discussions of pencil-and-paper activities.

The room was equipped with a Surfx Atomflo 300 plasma source [16] (other plasma sources can be used as well). This reactor is an atmospheric plasma jet that consists of two perforated rectangular plates separated by a gap $1.6 \mathrm{~mm}$ across. An atmospheric pressure plasma jet was generated by using a He flow of $20.4 \mathrm{~L} / \mathrm{min}$, and secondary gas flow $\left(\mathrm{N}_{2}\right.$ or $\left.\mathrm{O}_{2}\right)$. Both gases were industrial grade. The linear showerhead was placed perpendicularly $5 \mathrm{~cm}$ (unless otherwise noted) above the glass slide with the centers of both the glass slide and showerhead aligned.

A microliter pipette, and glass microscope slides were used. The glass slide had $4 \mu \mathrm{L}$ of water applied at its center. The plasma source was then activated alongside a timer and both were deactivated at a set time threshold. The lights in the room were dimmed to reduce the intensity of the reflection coming from the water and a camera was then placed perpendicular to the long axis of the water droplet. Digital images were taken to be analyzed by ImageJ [17] analysis software with its Contact Angle Plugin[18]. Experiments were performed in three repetitions. An image of the setup is pictured in Fig. 1.

The effects of the following parameters on contact angle were tested:

- Plasma power and exposure time (for two different secondary gases, $\mathrm{N}_{2}$, and $\mathrm{O}_{2}$ used in addition to the primary He gas), 


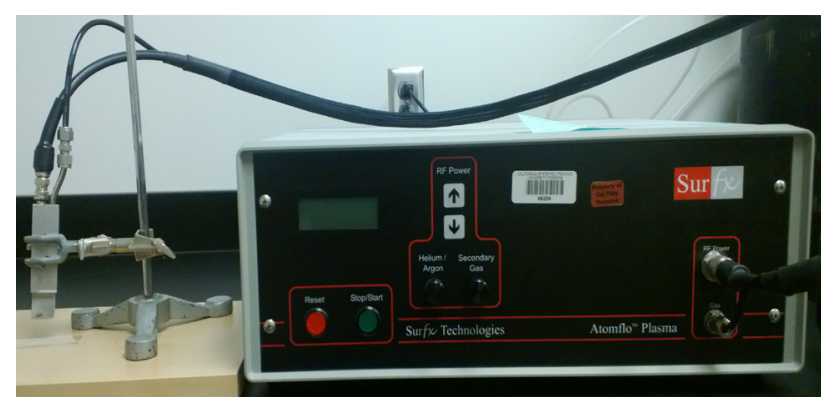

Figure 1. Experimental setup including the Surfx Atomflo with linear showerhead applicator used to treat the surface of a glass slide

- separation distance between the plasma source and the treated surface, and

- time duration following treatment.

\section{RESULTS}

\section{A. Nitrogen Power Variance}

Shown in Fig. 2 is a plot of contact angle vs. power for the secondary gas nitrogen. The threshold times were between 30 and 90 seconds with increments of 15 seconds. The plot shows that all treatments except the treatment at $25 \mathrm{~W}$ exhibit logarithmic characteristics whereas the $25 \mathrm{~W}$ plot exhibits an almost linear characteristic. The $35 \mathrm{~W}$ treatment shows the greatest decrease in contact angle and levels off after 60 seconds where the decrease in contact angle is only $2^{\circ}$ between 60 and 90 seconds. Curves for other applied powers in Fig. 2 also begin to plateau at about the same time with changes in contact angle for the same time interval of $7^{\circ}, 6^{\circ}$, and $4^{\circ}$ for $20 \mathrm{~W}$, $25 \mathrm{~W}$, and $30 \mathrm{~W}$, respectively.

\section{B. Oxygen Power Variance}

Shown in Fig. 3 is a plot of contact angle vs. power for the secondary gas oxygen. The threshold times were the same as for nitrogen varying between 30 s and 90 s. In all variances of power, the contact angle was logarithmically decreasing with respect to time except in the case of a radio frequency power of $40 \mathrm{~W}$. In the case of the $40 \mathrm{~W}$ curve, the curve ends abruptly at 70 s where the next interval of $75 \mathrm{~s}$ was not measurable. This loss of data is due to the fact that our cameras could not resolve contact angles that low and further increases in time only resulted in the surface growing closer to complete wetting.

\section{Distance Variance}

Shown in Fig. 4 is a linear plot of contact angle vs. distance $( \pm .5 \mathrm{~cm})$. It is clear from the plot that shorter showerhead distances generally result in smaller contact angles. The increase in contact angle is approximately linear with showerhead distance up to a distance of approximately 8 $\mathrm{cm}$ at which point contact angle plateaus.

\section{Time After Treatment Variance}

Change in contact angle with time following treatment is shown in Fig. 5. Contact angle was measured at intervals of 7 to 11 hours for the 96 hours after the plasma treatment ceased. For post-treatment times less than 48 hours, the contact angle could not be resolved due to surface approaching the state of complete wetting. Over the next five intervals contact angle increased linearly until about 96 hours at which point the contact angle reached a value of $35^{\circ}$ equal to the contact angle for an untreated surface.

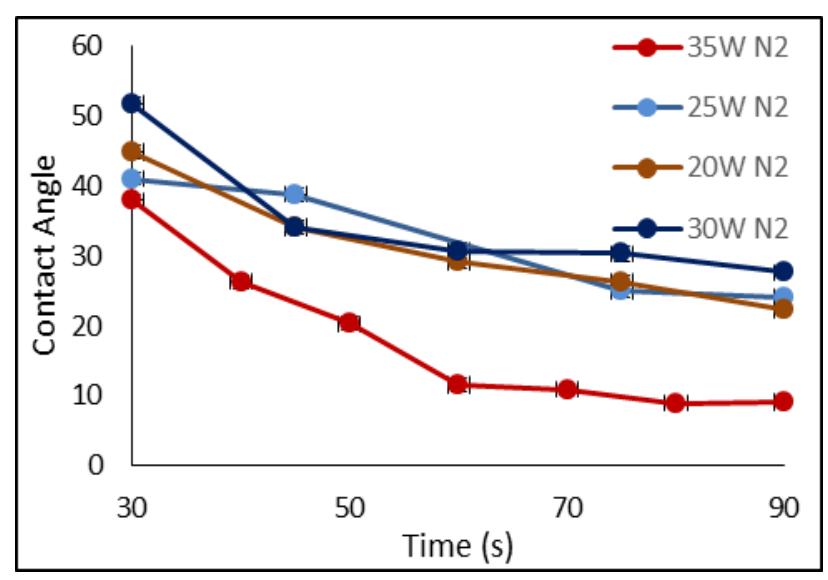

Figure 2. Contact Angle vs. Time for Nitrogen

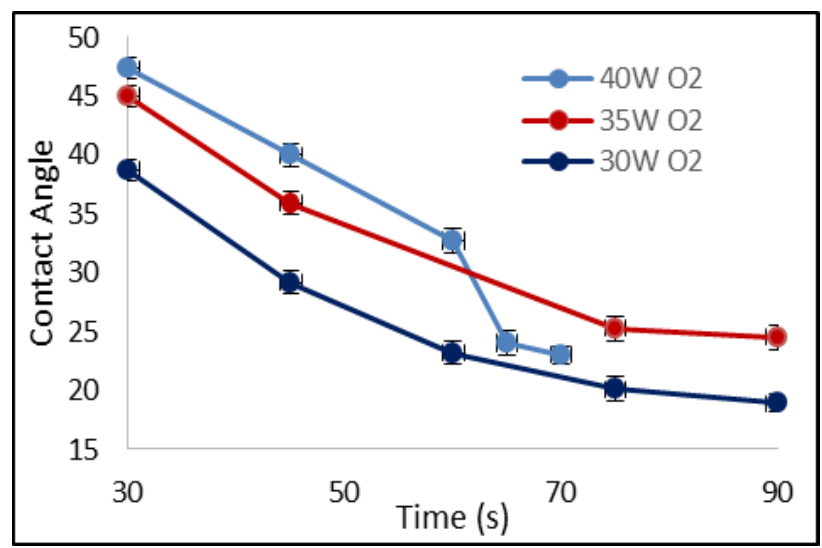

Figure 3. Contact Angle vs. Time for Oxygen

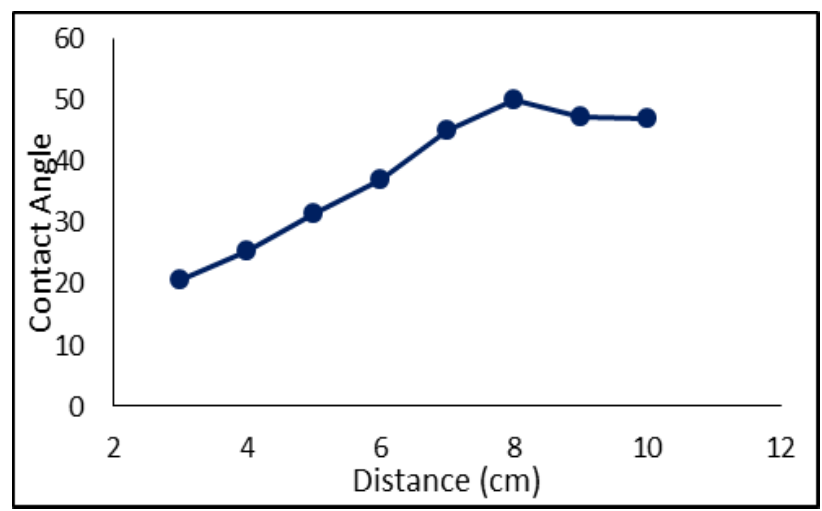

Figure 4. Contact Angle vs. Distance Between Showerhead and Glass

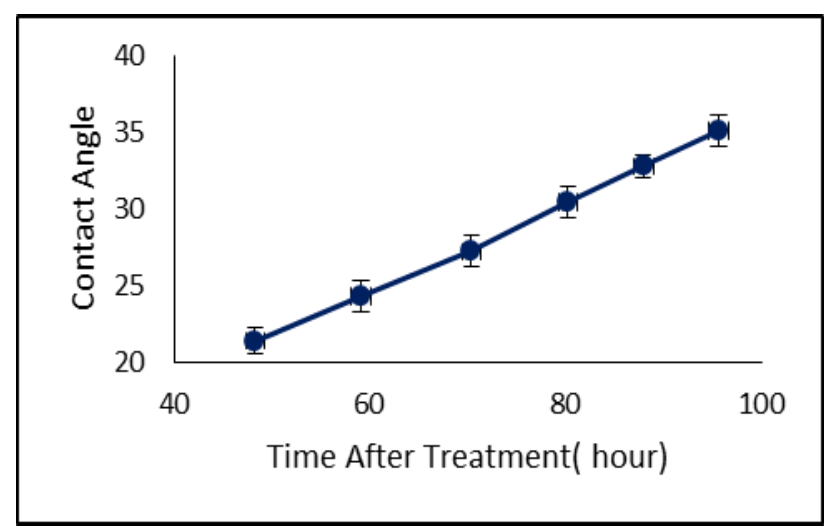

Figure 5. Contact Angle vs. Time after the Surface had been treated 


\section{INQUIRY BASE EXPERIMENT: THE EFFECT OF PlASMA ON GLASS SURFACE PROPERTIES}

\section{CONCLUSION}

In this paper we have shown an example implementation of a research-like and inquiry-based experiment for an undergraduate plasma course. This experiment gave students hands-on experience while verifying concepts learned in class. This experiment demonstrates to students the effect of plasma on surface properties. It requires them to assess the various ways that the contact angle of a glass-water interface reacts to changes in distance, radio frequency power, flow rate, and time after being treated.

\section{REFERENCES}

[1] J. Bransford, A. Brown, and R. Cocking, How People Learn: Brain, Mind, Experience, and School. (National Academy Press, Washington, DC, 2000).

[2] J. Bransford and M. Donovan, How Students Learn: History, Mathematics, and Science in the Classroom. (National Academy Press, Washington, DC, 2005).

[3] Bonwell, C.C., and J. A. Eison, "Active Learning: Creating Excitement in the Classroom," ASHEERIC Higher Education Report No. 1, George Washington University, Washington, DC , (1991).

[4] McDermott, L. C. What We Teach and What is Learned - Closing the Gap, American Journal of Physics 59, 301-315 (1991). http://dx.doi.org/10.1119/1.16539

[5] L. McDermott and E. Redish., "Resource Letter: PER-1: Physics Education Research," Am. J. Phys. 67 (755) (1999). http://dx.doi.org/10.1119/1.19122

[6] [6] R. Hake, "Interactive-engagement vs traditional methods: A six-thousand-student survey of mechanics test data for introductory physics courses. ," Am. J. Phys. 66, 64-74 (1998). http://dx.doi.org/10.1119/1.18809

[7] Wieman, C., \& Perkins, K. 2005, "Transforming Physics Education," Physics Today, 58(11), 36. http://dx.doi.org/10.1063/ 1.2155756

[8] Flora, J. and Cooper, A., , Incorporating Inquiry-Based Laboratory Experiment in Undergraduate Environmental Engineering Laboratory (doi: 10.1061/(ASCE)1052-3928(2005)131:1(19))

[9] Rutten, N., van der Veen, J. T., \& van Joolingen, W. R. (2015). Inquiry-Based Whole-Class Teaching with Computer Simulations in Physics.International journal of science education, 37(8), 12251245. http://dx.doi.org/10.1080/09500693.2015.1029033

[10] Vavougios, D., \& Karakasidis, T. (2008). Application of ICT technology in physics education: teaching and learning elementary oscillations with the aid of simulation software. International Journal of Emerging Technologies in Learning (iJET), 3(2), 53-58.

[11] Lopatto, D. (2003). The essential features of undergraduate research. Council on Undergraduate Research Quarterly, 24 , 139142.

[12] Seymour, E., Hunter, A-B., Laursen, S.L., \& DeAntoni, T. (2004). Establishing the benefits of research experiences for undergradu- ates in the sciences: first findings from a three-year study. Sci Educ. 2004;88:493-534. http://dx.doi.org/10.1002/sce.10131

[13] Conzone, S.D., Pantano, C.G., 2004. Glass slides to DNA microarrays. Mater. Today 7 (3), 20-26. Photopolym. Sci. Technol. 10 (1), 91-112.

[14] De Geyter, R. Morent, C. Leys, L. Gengembre, E. Payen, S. Van Vlierberghe, and E. Schacht, Surf. Coat. Technol. 202, 3000 2008.

[15] Cheruthazhekatt, Sadiqali, Mirko Černák, Pavel Slavíček, and Josef Havel. "Gas Plasmas and Plasma Modified Materials in Medicine." Journal of Applied Biomedicine 8.2 (2010): 55-66. http://dx.doi.org/10.2478/v10136-009-0013-9

[16] Schutze, Andreas, James Jeong, Steven Babayan, Jaeyoung Park, Gary Selwyn, and Robert Hicks. "He Atmospheric-Pressure Plasma Jet: A Review and Comparison to Other Plasma Sources." IEEE Transactions on Plasma Science 26.6 (1998): 1685-694. http://dx.doi.org/10.1109/27.747887

[17] Rasband, W. ImageJ, version 1.46; National Institue of Health; http://rsbweb.nih.gov/ij/ (accessed Apr. 2013)

[18] Brugnara, M. Contact Angle plugin (for ImageJ software), 2006; marco.brugnara@ing.intn.it; http://rsbweb.nih.gov/ij/plugins/cont act-angle.html (accessed Apr. 2013)

\section{AUTHORS}

L.R. Kabot was an undergraduate student majoring in Physics in the Physics and Astronomy Department, Cal Poly Pomona, $3801 \mathrm{~W}$ Temple Ave, Pomona, CA USA 91768.

T. M. Worden was an undergraduate student majoring in Physics in the Physics and Astronomy Department, Cal Poly Pomona, Pomona, 3801 W Temple Ave, Pomona, CA USA 91768.

A. K. Matsushita was an undergraduate student majoring in Physics in the Physics and Astronomy Department, Cal Poly Pomona, $3801 \mathrm{~W}$ Temple Ave, Pomona, CA USA 91768.

R.X. Hernandez was an undergraduate student majoring in Physics in the Physics and Astronomy Department, Cal Poly Pomona, $3801 \mathrm{~W}$ Temple Ave, Pomona, CA USA 91768.

N. Abramzon is a professor of Physics in the Physics and Astronomy Department, Cal Poly Pomona, 3801 W Temple Ave, Pomona, CA USA 91768 (email: nabramzon@cpp.edu)

Submitted 30 November 2015. Published as resubmitted by the authors 26 January 2016. 